\title{
Finite Element CAD Experiments on the Effect of Magnetic Loss in Power Transformers with Laminated Cores
}

\author{
Antônio Flavio Licarião Nogueira*, Rodolfo Lauro Weinert, \\ Leonardo José Amador Salas Maldonado \\ Department of Electric Engineering, Santa Catarina State University, Joinville, Santa Catarina, Brazil \\ Email: *antonioflavio.licariaonogueira@gmail.com
}

How to cite this paper: Nogueira, A.F.L., Weinert, R.L. and Maldonado, L.J.A.S. (2021) Finite Element CAD Experiments on the Effect of Magnetic Loss in Power Transformers with Laminated Cores. Journal of Electromagnetic Analysis and Applications, 13, 1-19.

https://doi.org/10.4236/jemaa.2021.131001

Received: December 20, 2020

Accepted: January 26, 2021

Published: January 29, 2021

Copyright $\odot 2021$ by author(s) and Scientific Research Publishing Inc. This work is licensed under the Creative Commons Attribution International License (CC BY 4.0).

http://creativecommons.org/licenses/by/4.0/

(c) (i) Open Access

\begin{abstract}
The paper describes a simulated experiment that focuses on the numeric computation of magnetic loss in the laminated core of a single-phase power transformer. The students' laboratory work is part of the library of experiments of the Electrical Machines virtual laboratory and makes use of the two-dimensional open-access electromagnetic field analysis software Finite Element Method Magnetics. The idea of the simulated exercise is to demonstrate how the magnetic loss caused by time-varying excitations affects the magnetic permeability, $\mu$, of the laminated core and the terminal quantities of the energizing winding. A parametric analysis employing different values for the electrical conductivity and maximum hysteresis-induced angle of the laminated material yields five different field problems with increasing magnetic loss. Electric circuits characterized by the $(I-V)$ operating point and reflected impedance of the energizing winding provide the information required to compute the changes in real power $\Delta P$, reactive power $\Delta Q$ and magnetically stored energy $\Delta W_{\mathrm{m}}$ between successive problems characterized by increasing magnetic loss. The concept of reflected impedance helps to explain the physical meaning of the changes in power dissipation and energy storage in the laminated core.
\end{abstract}

\section{Keywords}

Eddy Currents, Electromagnetic Engineering Education, Finite Element Analysis, Hysteresis, Magnetic Loss, Transformer Cores

\section{Introduction}

Most power transformers employ thin laminations in their ferromagnetic cores 
in the attempt to reduce eddy current effects. The material used for transformer cores is grain-oriented silicon-iron. The laminated material is hot-rolled then cold worked twice, followed by an anneal to improve the grain orientation and increasing the permeability along the rolling direction [1]. Eddy currents flow close to the surface of the thin laminations and their thickness is less or equal to the depth of penetration. Typical thickness of silicon-iron laminations range from 0.23 to $0.35 \mathrm{~mm}$, so eddy currents in thin laminations are restricted by the high resistivity of the laminated material and lack of space [2].

In two-dimensional (2-D) finite-element analysis, transformers are modeled as planar structures with longitudinal symmetry. In the analysis, both driving currents and induced currents flow in the longitudinal or $z$-direction. A detailed discussion on the numeric modeling of magnetic devices with longitudinal symmetry has been recently published and appears in [3]. Within a 2-D finite element framework, the laminated core is treated as an anisotropic medium, and the analysis program implements an approximate bulk model for the core based on the concept of effective permeability [4]. In this type of numeric modeling, the orientation of the ferromagnetic core is said to be "laminated in plane", i.e., parallel to the plane of analysis, as illustrated in the sketch of the test transformer's core shown in Figure 1. The simulated experiment described in this paper is carried out employing the two-dimensional open-access simulation software "Finite Element Method Magnetics" (FEMM) [5]. Similar experiments using the FEMM CAD system to approach axially-symmetric problems appear in [6].

Finite Element Method Magnetics (FEMM) is a suite of programs for solving low-frequency electromagnetic problems on two-dimensional planar and axisymmetric domains. The program currently addresses linear and non-linear magnetostatic problems, linear and non-linear time-harmonic magnetic problems, linear electrostatic problems, and steady-state heat flow problems. Its main advantage is the low computational cost and its ease of use. Despite these advantages, the software does not address three-dimensional planar problems, cannot be used to analyze transient $A C$ problems, and can only operate as a voltage-driven program under batch-run analysis mode [7]. The FEMM CAD package is very popular among research students, scientists and engineers [8]. In

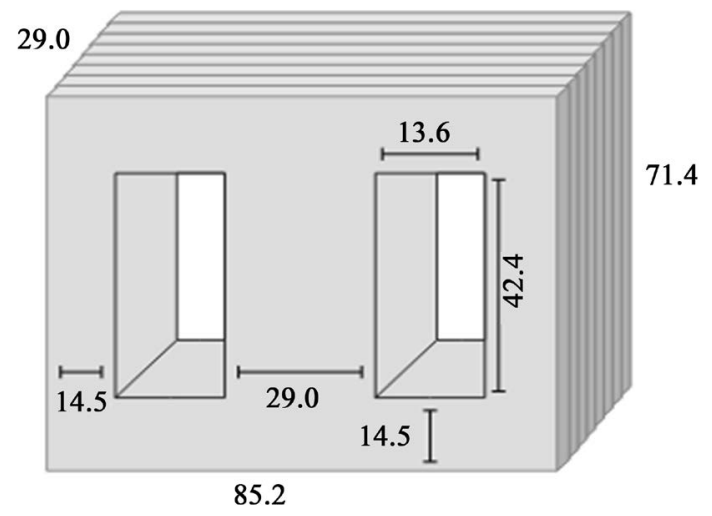

Figure 1. Sketch of the laminated core. Dimensions in $\mathrm{mm}$. 
his discussion about the use of the package as an educational tool, K.B. Baltzis [9] gives emphasis to an extensive list of the software applications in different fields of knowledge, viz: electromagnetics [10], electric machines [11], materials science [12], industrial design [13], biological sciences [14], particle physics [15], robotics [16], and astronomy [17].

The proposed CAD experiment focuses on the computation of the no-load magnetic loss in the laminated core of a single-phase shell-type power transformer using the non-linear finite element time-harmonic technique. This technique is an enhancement of modern electromagnetic field analysis programs that approximately models the effects of saturation and hysteresis on the fundamental component of the $\boldsymbol{B}$-field, for different levels of the sinusoidal excitation represented by the $H$-field.

The main objectives of the experiment are:

- Inspection of computed values of the complex permeability, $\mu$, at different locations of the ferromagnetic core;

- Determination of terminal quantities of the energizing winding, viz. terminal voltage, inductive impedance, active power and reactive power;

- Determination of the change in real power and reactive power that occurs in successive field problems with increasing magnetic loss.

The design of the test transformer including the relationship between the core's geometry and rated power, choice of windings and assembly of the laminated core is based on the design rules presented in [18]. In the test transformer, the coils that form the primary and secondary circuits are wound around the core's central limb. The low-voltage circuit is wound over the top of the highvoltage circuit, and is formed by the series connection of five identical windings with 30 turns each. Rated values of the test transformer are summarized in Table 1.

\section{Magnetic Loss and Its Effects}

Micro and macro-eddy currents present in the magnetic core of an electric equipment produce ohmic loss and their own magnetic field-known as reaction field-that opposes the flux change originated by alternating excitations [19]. Magnetic loss causes a variation in the magnetic permeability, $\mu$, of the ferromagnetic core, and this variation can be investigated using different approaches.

Table 1. Rated values of the test transformer.

\begin{tabular}{ccc}
\hline Design parameter & High-voltage winding & Low-voltage winding \\
\hline $\mathrm{N}^{\circ}$ of turns & 1100 & 150 \\
Apparent power (VA) & 58.0 & 58.0 \\
RMS voltage (V) & 220.0 & 30.0 \\
RMS current (A) & 0.26364 & 1.93333 \\
Peak current (A) & 0.37284 & 2.73415 \\
Type of conductor & 28 AWG & 24 AWG \\
\hline
\end{tabular}


In a magnetically linear time-harmonic solution, the permeability $\mu$ of the core is complex-valued and has the same value in the whole volume occupied by the laminated core. In non-linear problems, the value of the permeability varies from point to point in the region of the laminated core. The effect of increasing magnetic losses on terminal quantities like the active power $P$ and reactive power $Q$ can be readily inspected using the concept of reflected impedance of the energizing winding introduced in section 5.3.

In periodic field problems formulated with the $H$ - and $B$-fields expressed in terms of phasor vector quantities, two distinct situations should be considered: (i) the effect of magnetic loss is negligible and, as illustrated in Figure 2(a), vectors $\boldsymbol{H}$ - and $\boldsymbol{B}$-possess the same phase angle; and (ii) the effect of magnetic loss is considerable, and can be included in the analysis by introducing a time-phase difference between the $\boldsymbol{H}$-and $\boldsymbol{B}$-fields, defined as the hysteresis angle $\phi_{\mathrm{h}}$ of the magnetic material. This effect is known as hysteresis-induced lag, and is illustrated in the diagram of Figure 2(b). In this situation, the $\boldsymbol{B}$-field lags the $H$-field by a fixed phase angle, the magnetic permeability is a complex quantity, and the corresponding $B-H$ characteristic becomes elliptical. A brief discussion on the definitions of complex-valued permeabilities in time-harmonic problems is presented in Appendix A.

The vector fields $\boldsymbol{H}$ and $\boldsymbol{B}$ that produce the approximate elliptical hysteresis loop are calculated from two terminal quantities of the energizing winding, viz. the driving current $I$ and the flux linkage $\lambda$, respectively. The value of the flux linkage is furnished by the finite-element solver together with the other winding's circuit properties like total voltage drop and reflected impedance. Initially, let us consider the no-load operation of the test transformer. In the experiment, the 1100-turn high-voltage winding is kept open-circuited, and the 150-turn lowvoltage winding is supplied by a $60 \mathrm{~Hz}$ sinusoidal current $I$. The magnitude of the no-load driving current is usually very small, and ranges from $1 \%$ to $5 \%$ of the winding's rated current. Let $H$ and $B$ represent the phasor vectors computed from the driving current $I$ and computed flux linkage $\lambda$ with the exciting winding, respectively. According to Ampère's circuital law, the magnetic field strength $H$ is directly proportional to the driving current $I$ and given by

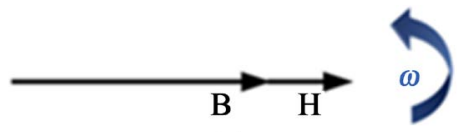

(a)

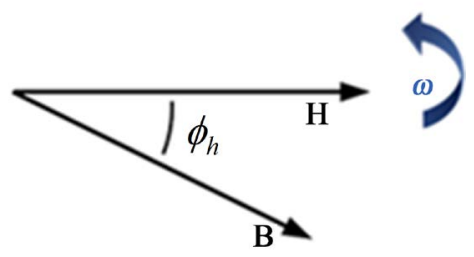

(b)

Figure 2. (a) The effect of magnetic loss is negligible ; (b) The effect of magnetic loss is considerable. 


$$
\boldsymbol{H}=\left(\frac{N}{l_{m}}\right) \boldsymbol{I},
$$

where $N$ is the number of turns of the exciting winding and $I_{\mathrm{m}}$ is the mean value of the closed path that encircles the magnetomotive force NI. The magnetic induction $B$ is directly proportional to the flux linkage $\lambda$ and given by

$$
\boldsymbol{B}=\frac{1}{(N A)} \lambda,
$$

where $A$ is the cross-sectional area of the shell-type transformer's central limb.

Important bulk magnetic properties of the material employed in the ferromagnetic core of machines and transformers can be obtained from the hysteresis loop. During a cyclic magnetization process, magnetic energy is converted into thermal energy and the amount of loss can be computed from the $\boldsymbol{B}$ - $\boldsymbol{H}$ plot or hysteresis loop. The area enclosed by the hysteresis loop gives the density of thermal energy, $W_{\mathrm{h}}$, dissipated on completion of a magnetization cycle and is computed by

$$
W_{\mathrm{h}}=\oint H \mathrm{~d} B .
$$

If the operating frequency is $f$, the power loss, $P_{\mathrm{h}}$, in units of watt is computed by

$$
P_{\mathrm{h}}=(\oint H \mathrm{~d} B) V f,
$$

where $V$ is the volume of magnetic material. When post-processing the field solution in the FEMM CAD system, it is necessary to select the region occupied by the laminated core and choose the task "total losses" from the drop list of numeric integrations.

\section{Parametric Analysis}

Electromagnetic field simulators contain a built-in library to facilitate the access to materials data files. The library for problems of magnetism contains several material property files of materials commonly used in the industry of electric equipment separated in file directories for conductors, permanent magnets and soft magnetic materials. The data file of a soft magnetic material may contain all necessary information to fully characterize the ferromagnetic core of a power transformer, i.e., $1^{\text {st }}$ quadrant $B$ - $H$ curve, loss curves, initial relative permeability, electric conductivity of laminations, lamination thickness and lamination fill factor. The physical properties and special attributes that characterize the M-36 steel laminated core of the test transformer are summarized in the block scheme of Figure 3. The magnetization characteristic for the M-36 steel is shown in Appendix B.

To investigate the effect of magnetic loss on the various electromagnetic quantities of the test transformer, a parametric analysis has been carried out. The two parametric quantities are the electric conductivity $\sigma$ of the laminations 
and the specified maximum hysteresis-induced angle $\phi_{\text {hmax }}$. Five different configurations of the laminated core have been considered, and the parameters that characterize each field problem are highlighted in the block scheme of Figure 4. In the first field problem, magnetic losses are not included, and both the maximum hysteresis angle $\phi_{\mathrm{hmax}}$ and the electric conductivity $\sigma$ of the steel laminations are specified as zero. The other four field problems concern a lossy laminated core and are distinguished by the value specified for the maximum hysteresis angle $\phi_{\mathrm{hmax}}$. In these four problems, the electric conductivity of the steel laminations is specified as $\sigma=2 \times 10^{6} \mathrm{~S} / \mathrm{m}$.

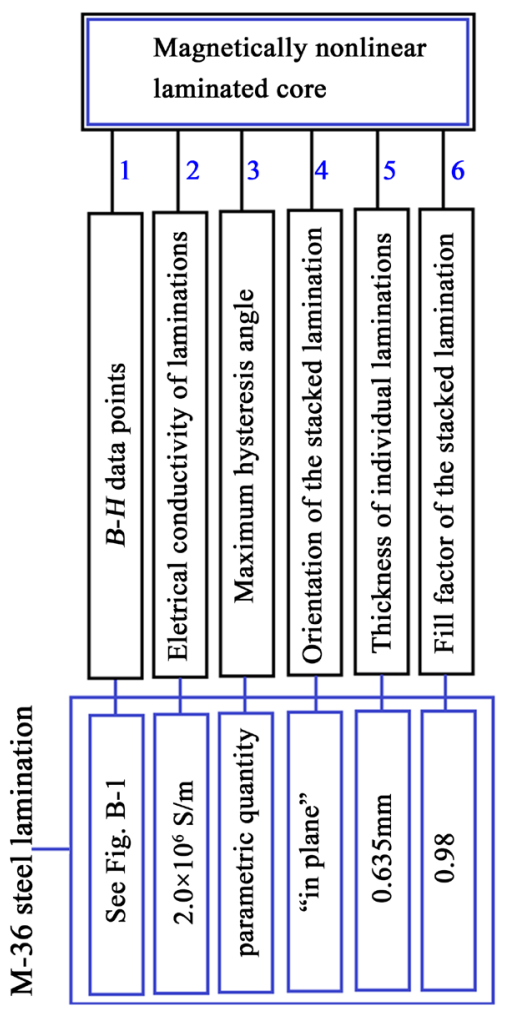

Figure 3. Physical properties and special attributes of the M-36 laminated core.

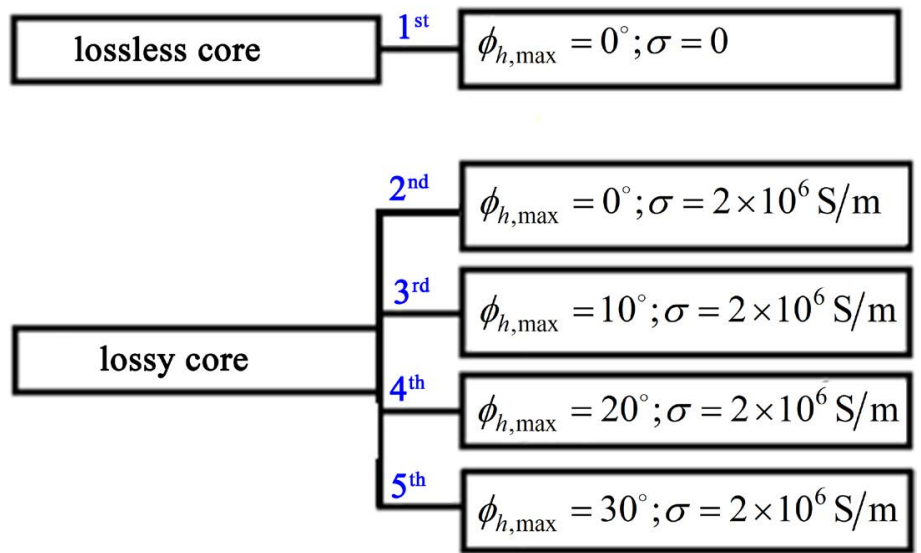

Figure 4. Parametric analysis based on five different configurations of the M-36 laminated core. 


\section{Problem Definition}

In the simulated work, the five time-harmonic problems are distinguished by different operating points $(I, V)$ consisting of driving current $I$ and estimated terminal voltage $\boldsymbol{V}$. In a current-driven finite-element program, the simulation of no-load operating conditions in transformers and electric machines involves difficulties, and these are mainly related to the choice of the driving current. When the classical open-circuit test is carried out in the laboratory, the transformer operates with sinusoidal applied voltage but nonsinusoidal current. Whereas the winding rated voltage is well known as part of the transformer's ratings, the magnetizing current must be measured or estimated, either analytically or numerically using, e.g., the method described in [20]. In the simulation of no-load operating conditions, the distorted magnetizing current of the transformer can only be used as the driving current if the analysis is based on the time-step technique. In time-harmonic analysis, the driving current must be sinusoidal.

Five different sequences of problems driven by sinusoidal currents with increasing magnitudes have been used to identify the best fit match between the driving current-taken as the independent variable-and the rated voltage. In each sequence of problems, the magnitude of the sinusoidal driving current varies from $1.0 \%$ to $5.0 \%$ of the low-voltage winding's rated current. Each sequence is related to one of the core configurations indicated in the block scheme of Figure 4. As indicated in Table 1, the "rms" rated values for the winding's voltage and current are $30 \mathrm{~V}$ and $1.93 \mathrm{~A}$, respectively. In terms of peak values, the rated voltage and rated current are $42.43 \mathrm{~V}$ and $2.73 \mathrm{~A}$, respectively. The results of the simulations are presented in the graph of Figure 5 .

In the graph of Figure 5, the horizontal solid line represents the rms value of the winding's rated voltage, $V_{\text {rated }}=30 \mathrm{~V}$. Each characteristic representing the increase in terminal voltage is associated to a different parametric analysis. To

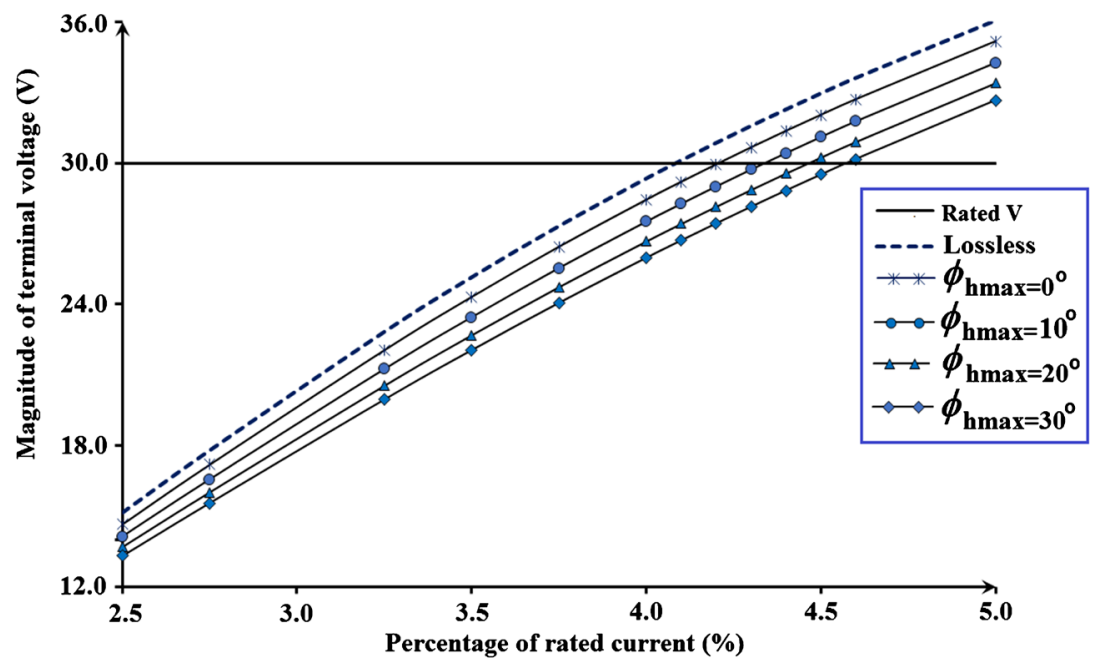

Figure 5. Variation of terminal voltage with respect to the magnitude of the driving current. 
simulate a permeable but lossless magnetic core, both the maximum hysteresis angle $\phi_{\text {hmax }}$ and the electric conductivity $\sigma$ of the steel laminations are specified as zero. The dashed characteristic represents the results of the lossless core configuration. The four characteristics that represent a lossy laminated core are distinguished by the value specified to the maximum hysteresis angle: (i) for the characteristic marked with "*”, $\phi_{\mathrm{hmax}}=0^{\circ}$; (ii) for the characteristic marked with “", $\phi_{\mathrm{hmax}}=10^{\circ}$; (iii) for the characteristic marked with “ $\boldsymbol{\Delta}$ ", $\phi_{\mathrm{hmax}}=20^{\circ}$; and (iv) for the characteristic marked with " $", \phi_{\mathrm{hmax}}=30^{\circ}$.

\section{Results}

\subsection{Operating Points $(I, V)$}

Observation of the graph presented in Figure 5 shows that the five characteristics trace similar courses along the simulated excursion. The point in the $(I-V)$ plane where each curve representing the increase in terminal voltage intercepts the horizontal characteristic that represents the rated voltage indicates the required driving current. The driving current that yields the best fit match to the rated voltage ( $\left.V_{\text {rated }}=30 \mathrm{~V}, \mathrm{rms}\right)$ differs for each sequence of problems. For the lossless core configuration $\left(\sigma=0 ; \phi_{\text {hmax }}=0^{\circ}\right)$, the best fit match to the rated voltage occurs when the driving current represents $4.1 \%$ of the winding's rated current. For each sequence of simulations, the value of the required driving current that yields a terminal voltage close to the rated value is indicated in the $4^{\text {th }}$ and $5^{\text {th }}$ columns of Table 2. Five pairs $(I, V)$ consisting of driving current and estimated voltage define the transformer operating points for the five parametric analysis.

\subsection{Flux Linkage and Terminal Voltage}

Results of the parametric analysis are presented in the following. Magnitudes and phase angles of the computed flux linkages are indicated in the $6^{\text {th }}$ and $7^{\text {th }}$ columns of Table 2. The graphical representation of driving currents and flux linkages is shown in the vector diagram of Figure 6. Given the small difference in the magnitude of the five driving currents, a unique vector, $I$, with phase angle of $0^{\circ}$ is exhibited in the diagram. The five vectors, $\lambda_{1}$ to $\lambda_{5}$, are basically distinguished by their lag phase angle with respect to the reference vector $I$. The

Table 2. Driving currents and flux linkages.

\begin{tabular}{ccccccc}
\hline \multirow{2}{*}{$\begin{array}{c}\text { Type of } \\
\text { analysis }\end{array}$} & \multicolumn{2}{c}{ Parametric quantities } & \multicolumn{2}{c}{ Driving current } & \multicolumn{2}{c}{ Flux linkage $\lambda$} \\
\cline { 2 - 6 } & $\begin{array}{c}\text { Conductivity } \\
(\mathrm{S} / \mathrm{m})\end{array}$ & $\begin{array}{c}\text { Max. hyst. } \\
\text { angle (degree) }\end{array}$ & $\begin{array}{c}\text { \% of } \\
I_{\text {rated }}\end{array}$ & $\begin{array}{c}\text { Peak value } \\
(\mathrm{mA})\end{array}$ & $\begin{array}{c}|\lambda| \text {, (peak) } \\
\text { (milliweber) }\end{array}$ & $\begin{array}{c}\lambda \text { (angle) } \\
\text { (degree) }\end{array}$ \\
\hline Lossless & 0 & 0 & 4.10 & 112.10 & 112.92 & $-8.3 \times 10^{-7}$ \\
Hysteretic & $2 \times 10^{6}$ & 0 & 4.20 & 114.83 & 112.29 & -11.7 \\
Hysteretic & $2 \times 10^{6}$ & 10 & 4.30 & 118.94 & 111.40 & -20.6 \\
Hysteretic & $2 \times 10^{6}$ & 20 & 4.50 & 123.04 & 113.37 & -29.3 \\
Hysteretic & $2 \times 10^{6}$ & 30 & 4.60 & 125.77 & 113.05 & -37.7 \\
\hline
\end{tabular}




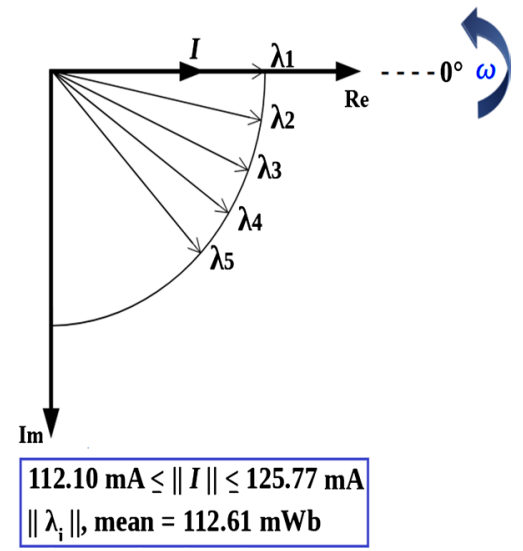

Figure 6. Graphical representation of driving currents and flux linkages.

Table 3. Driving currents and terminal voltages.

\begin{tabular}{cccccccc}
\hline \multirow{2}{*}{$\begin{array}{c}\text { Type of } \\
\text { analysis }\end{array}$} & \multicolumn{2}{c}{ Parametric quantities } & \multicolumn{2}{c}{ Driving current } & \multicolumn{3}{c}{ Estimate to rated voltage } \\
\cline { 2 - 8 } & $\begin{array}{c}\text { Conductivity } \\
(\mathrm{S} / \mathrm{m})\end{array}$ & $\begin{array}{c}\text { Max. hyst. } \\
\text { angle (degree) }\end{array}$ & $\begin{array}{c}\% \text { of } \\
I_{\text {rated }}\end{array}$ & $\begin{array}{c}\text { Peak value } \\
(\mathrm{mA})\end{array}$ & $\begin{array}{c}|V| \text { (peak) } \\
(\mathrm{V})\end{array}$ & $\begin{array}{c}\text { Angle } \\
(\text { degree })\end{array}$ & $\begin{array}{c}\text { Error in } \\
|V|(\%)\end{array}$ \\
\hline Lossless & 0 & 0 & 4.10 & 112.10 & 42.57 & 89.9 & 0.33 \\
Hysteretic & $2 \times 10^{6}$ & 0 & 4.20 & 114.83 & 42.35 & 78.3 & 0.19 \\
Hysteretic & $2 \times 10^{6}$ & 10 & 4.30 & 118.94 & 42.02 & 69.4 & 0.97 \\
Hysteretic & $2 \times 10^{6}$ & 20 & 4.50 & 123.04 & 42.77 & 60.7 & 0.79 \\
Hysteretic & $2 \times 10^{6}$ & 30 & 4.60 & 125.77 & 42.65 & 52.3 & 0.51 \\
\hline
\end{tabular}

radius of the arc that appears in the illustration-in the same length unit used to plot the vectors-is numerically equal to the mean value of the magnitude of flux linkages, $\left\|\lambda_{\mathrm{i}}\right\|_{\text {(mean) }}=112.61$ milliweber. The diagram clearly shows that, higher magnetic losses - originated by increasing ohmic loss and reaction fields in the laminated core -, lead to an increase in the time phase difference between the driving current and resulting winding's flux linkage.

Additional results of the parametric analysis are presented in Table 3. The actual estimates to the peak rated voltage, $V_{\text {rated }}=42.43 \mathrm{~V}$, are presented in the $6^{\text {th }}$ and $7^{\text {th }}$ columns of Table 3 . Observation of the percent errors indicated in the $8^{\text {th }}$ column shows that, in the five field solutions, the error in the magnitude of the estimates to the rated voltage is very small and below $1.0 \%$. The graphical representation of driving currents and terminal voltages is shown in the vector diagram of Figure 7. The five vectors, $V_{1}$ to $V_{5}$, are basically distinguished by their leading phase angle with respect to the reference vector $I$. The radius of the arc that appears in the illustration-in the same length unit used to plot the vectors-is numerically equal to the mean value of the magnitude of voltage estimates, $\left\|\mathrm{V}_{\mathrm{i}}\right\|$, mean $=42.47 \mathrm{~V}$.

\subsection{Reflected Impedances}

Eddy currents and hysteresis make the flux linkage $\lambda$ lag the terminal current $I$, 


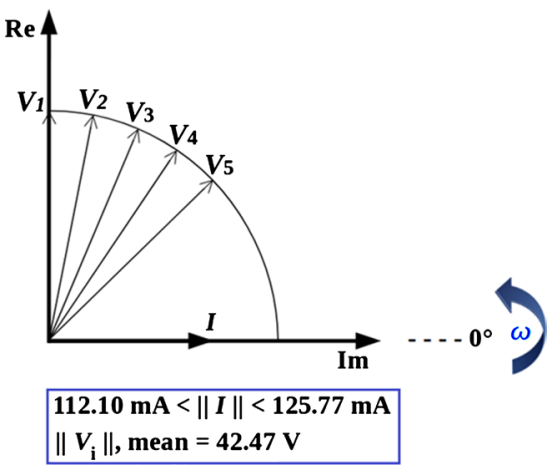

Figure 7. Graphical representation of driving currents and terminal voltages.

and make the inductance of the energizing winding complex-valued [21]. The complex inductance $L$ is defined as

$$
L=\lambda / \boldsymbol{I}
$$

where $\lambda$ is the flux linkage with the winding and $I$ is the terminal current. The complex inductance $L$ can be decomposed as

$$
L=L_{\mathrm{r}}-j L_{\mathrm{i}},
$$

where $L_{\mathrm{r}}$ and $L_{\mathrm{i}}$ are the real and imaginary components of $L$, respectively. The implied inductive impedance, $Z$, is given by

$$
Z=j \omega L,
$$

where $\omega$ is the angular frequency of excitation. Substitution of the right-hand side of (6) into (7) leads to

$$
Z=\omega L_{\mathrm{i}}+j \omega L_{\mathrm{r}} .
$$

The electric circuit that represents the energizing winding of the test transformer at no-load operation is shown in Figure 8. In this circuit, $I_{S}$ denotes the specified sinusoidal driving current, and $V_{\mathrm{S}}$ denotes the computed terminal voltage. According to the terminology used by Stoll [2], the summation on the RHS of (8) is called "reflected impedance". If the intrinsic $D C$ resistance $R$ of the energizing winding is negligible, the total impedance of the winding can be approximated by the reflected impedance $Z$. The complex-valued reflected impedance $Z$ is formed by two lumped elements, to know:

- the $\omega L_{\mathrm{i}}$ term is the frequency-dependent circuit's resistance. This circuit element is known as the winding's "reflected resistance" because it represents the ohmic loss set up by eddy currents in the magnetic core and drawn from the energy supply;

- the $\omega L_{\mathrm{r}}$ term is the frequency-dependent circuit's inductive reactance. This circuit element is known as the winding's "modified reactance" because its calculation considers the reduction in the flux-carrying capacity of the core caused by the reaction field created by the eddy currents present in the laminated core.

For the five different configurations of the laminated core, the values of the driving currents, $I_{S}$, are those indicated in the $5^{\text {th }}$ line of Table 3 . In all simula- 
tions, the phase angle of the driving current is $0^{\circ}$. The magnitude and phase angle of the computed terminal voltages, $V_{\mathrm{s}}$, are indicated in the $6^{\text {th }}$ and $7^{\text {th }}$ columns of Table 3. Values of the circuit elements $\omega L_{\mathrm{i}}$ and $\omega L_{\mathrm{r}}$ are indicated in the $3^{\text {rd }}$ and $4^{\text {th }}$ columns of Table 4 . Values of computed real power $P$ and reactive power $Q$ are presented in the $6^{\text {th }}$ and $7^{\text {th }}$ columns of Table 4, and are also illustrated graphically in the bar graph of Figure 9.

\subsection{Discussion}

The illustration shown in the bar graph of Figure 9 helps to explain the change in the impedance of the energizing winding originated by the presence of eddy currents in the laminated core. Observation of data presented in columns 3 and 4 of Table 4 shows that, each new configuration of the magnetic core leads to an increase in reflected resistance $\omega L_{1}$ and a reduction in the modified inductive reactance $\omega L_{\mathrm{r}}$. This change in reflected impedance implies: 1) an increase in the active power $P$ drawn from the source supply; 2 ) and a reduction in the flow of reactive power $Q$ in the energizing winding. Let $I$ denote the "rms" value of the prescribed current $I_{\mathrm{S}}$ in the circuit of Figure 8. The averaged active power, $P$, drawn from the supply is computed by

$$
P=\left(\omega L_{\mathrm{i}}\right) I^{2}
$$

and the reactive power, $Q$, is computed by

$$
Q=\left(\omega L_{\mathrm{r}}\right) I^{2} .
$$

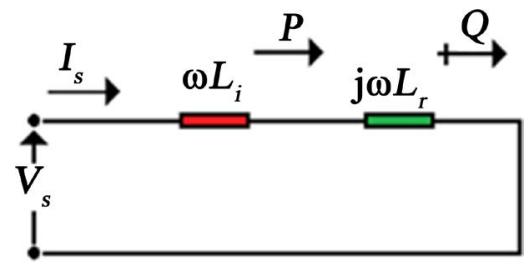

Figure 8. Electric circuit with frequency-dependent lumped elements.

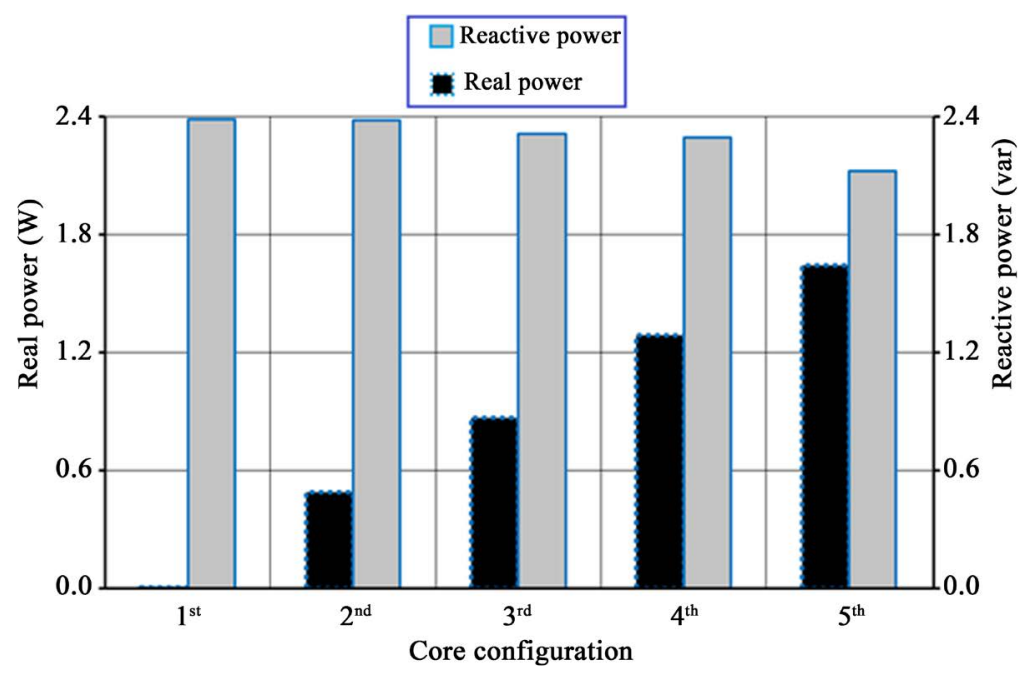

Figure 9. Values of real power and reactive power for the five core configurations. 
Let us now consider the changes in successive configurations, from the fourth to the fifth one, for example. In the fourth core configuration one has

$$
P_{4}=\underbrace{(169.93)}_{\omega L_{\mathrm{i}, 4}}(0.12304 / \sqrt{2})^{2}=1.286 \mathrm{~W}
$$

and

$$
Q_{4}=\underbrace{(303.24)}_{\omega L_{\mathrm{r}, 4}}(0.12304 / \sqrt{2})^{2}=2.295 \text { var. }
$$

In the fifth core configuration, one obtains $P_{5}=1.642 \mathrm{~W}$ and $Q_{5}=2.121$ var. These figures show that, the alteration in core configuration yields an increase of $27.7 \%$ in real power $P$ and a reduction of $7.58 \%$ in reactive power $Q$. According to data presented in the $8^{\text {th }}$ column of Table 4 , one observes that the magnetically stored energy in the two successive core configurations are $W_{\mathrm{m} 4}=3.04332$ $\mathrm{mJ}$ and $W_{\mathrm{m} 5}=2.81253 \mathrm{~mJ}$, respectively. As expected, both the magnetic stored energy $W_{\mathrm{m}}$ and the reactive power $Q$ undergo the same percent reduction of $7.58 \%$. The percent variations in real power, reactive power and magnetically stored energy that occur in the pairs of successive core configurations are summarized in Table 5.

Table 4. Reflected impedance, complex power and magnetically stored energy.

\begin{tabular}{ccccccc}
\hline & \multicolumn{3}{c}{ Inductive impedance } & \multicolumn{4}{c}{ Complex power } \\
\cline { 2 - 7 } Type of analysis & $\begin{array}{c}\omega L_{\mathrm{i}} \\
(\Omega)\end{array}$ & $\begin{array}{c}\omega L_{\mathrm{r}} \\
(\Omega)\end{array}$ & $\begin{array}{c}|Z| \\
(\Omega)\end{array}$ & $\begin{array}{c}\text { Real, } \boldsymbol{P} \\
(\mathrm{W})\end{array}$ & $\begin{array}{c}\text { Reactive, } \boldsymbol{Q} \\
(\mathrm{var})\end{array}$ & $\begin{array}{c}\text { Stored energy } \\
(\mathrm{m})\end{array}$ \\
\hline Lossless & 0.47 & 379.76 & 379.76 & $2.93 \times 10^{-3}$ & 2.38611 & 3.16403 \\
Hysteretic, $\phi_{\mathrm{hmax}}=\mathbf{0}^{\circ}$ & 74.70 & 361.12 & 368.76 & $4.92 \times 10^{-1}$ & 2.38084 & 3.15701 \\
Hysteretic, $\phi_{\mathrm{hmax}}=\mathbf{1 0}^{\circ}$ & 125.63 & 334.58 & 357.39 & $8.68 \times 10^{-1}$ & 2.31238 & 3.06618 \\
Hysteretic, $\phi_{\mathrm{hmax}}=\mathbf{2 0}$ & 169.93 & 303.24 & 347.60 & 1.28621 & 2.29520 & 3.04332 \\
Hysteretic, $\phi_{\mathrm{hmax}}=\mathbf{3 0 ^ { \circ }}$ & 207.59 & 268.20 & 339.16 & 1.64185 & 2.12122 & 2.81253 \\
\hline
\end{tabular}

Table 5. Percent variation in real power, reactive power and magnetically stored energy in successive core configurations.

\begin{tabular}{ccccc}
\hline Initial Configuration & Final Configuration & $\begin{array}{c}\text { Increase in } \\
\text { real power } \\
\Delta P(\%)\end{array}$ & $\begin{array}{c}\text { Reduction in } \\
\text { reactive power } \\
\Delta Q(\%)\end{array}$ & $\begin{array}{c}\text { Reduction in } \\
\text { stored energy } \\
\Delta W_{\mathrm{m}}(\%)\end{array}$ \\
\hline Lossless & Hysteretic, $\phi_{\mathrm{hmax}}=0^{\circ}$ & 168.0 & 0.22 & 0.22 \\
Hysteretic, $\phi_{\mathrm{hmax}}=0^{\circ}$ & Hysteretic, $\phi_{\mathrm{hmax}}=10^{\circ}$ & 76.0 & 2.88 & 2.88 \\
Hysteretic, $\phi_{\mathrm{hmax}}=10^{\circ}$ & Hysteretic, $\phi_{\mathrm{hmax}}=20^{\circ}$ & 48.0 & 0.74 & 0.74 \\
Hysteretic, $\phi_{\mathrm{hmax}}=20^{\circ}$ & Hysteretic, $\phi_{\mathrm{hmax}}=30^{\circ}$ & 27.7 & 7.58 & 7.58 \\
\hline
\end{tabular}

\section{Conclusions}

Electromagnetic CAD systems can be effectively used as complimentary tools in the teaching of subjects around electromagnetics. Electrical machines is consi- 
dered one of the most abstract and conceptually difficult subjects of the electrical engineering undergraduate curriculum, and this subject suffers from lack of student interest. The benefits of field simulations such as visualization of electromagnetic field distributions and enhanced capabilities to inspect phenomena of high complexity like magnetic saturation and distribution of eddy currents are determinant to overcome the difficulties inherent to the teaching of this subject.

The electrical machines virtual laboratory contains a series of experiments designed to teach complex electromagnetic phenomena. The experiments have been designed following recommendations of experts in engineering education and the authors' previous experience. In the laboratory of simulations, it is given emphasis on demonstrating how to set-up field problems for solution, and how to examine the numeric results critically.

In the experiment described in the paper, the students get acquainted with the finite element time-harmonic technique. This technique is very compact, computationally cheap, and can be used to advantage whenever the excitations are sinusoidal, and only the steady-state solution is needed. At the pre-processing stage, students are faced with the difficulties inherent to the choice of driving currents in current-driven finite element programs. The most important postprocessing task consists of building and analyzing the electric circuits that represent the sequence of field problems with increasing magnetic loss. Certainly, the experience gained in this laboratory meeting will be relevant to the student's future work in industry or academia.

\section{Acknowledgements}

The authors acknowledge the financial support, in the form of scholarships, from the Brazilian Federal Agency for Postgraduate Studies (CAPES). The authors give thanks to David Meeker (dmeeker@ieee.org) for the use of the finite element CAD system. The authors also give thanks to Dr. Benedito Antonio Luciano (benedito@dee.ufcg.edu.br) for the useful comments on the manuscript.

\section{Conflicts of Interest}

The authors declare no conflicts of interest regarding the publication of this paper.

\section{References}

[1] Jiles, D. (1991) Introduction to Magnetism and Magnetic Materials. Springer-Science + Business Media, Berlin. https://doi.org/10.1007/978-1-4615-3868-4

[2] Stoll, R.L. (1974) The Analysis of Eddy Currents. Oxford University Press, Oxford.

[3] Nogueira, A.F.L., Weinert, R.L. and Maldonado, L.J.A.S. (2019) Experiments for Teaching CAD Techniques Using Analytic and Finite Element Solutions of Electromagnetic Two-Dimensional Problems with Longitudinal Symmetry. Journal of Electromagnetic Analysis and Applications, 11, 79-99. https://doi.org/10.4236/jemaa.2019.116006

[4] Nogueira, A.F.L., Maldonado, L.J.A.S. and Weinert, R.L. (2020) Introduction to 
Time-Harmonic Analysis of Power Transformers with Laminated Cores Using the Electromagnetic Field Simulator Finite Element Method Magnetics. International Journal of Research and Reviews in Applied Sciences, 44, 9-24. https://www.arpapress.com/Volumes/Vol44Issue1/IJRRAS_44_1_02.pdf

[5] Meeker, D.C. (2013) Finite Element Method Magnetics, User's Manual, Version 4.2. http://www.femm.info/wiki/HomePage

[6] Nogueira, A.F.L., da Costa, V.H.P. and Weinert, R.L. (2017) Simulated Experiments for Teaching Mutually-Coupled Circuits CAD Techniques Using Analytic and Finite Element Solutions. Journal of Electromagnetic Analysis and Applications, 9, 183-202. https://doi.org/10.4236/jemaa.2017.911016

[7] Meeker, D.C. (2006) Finite Element Method Magnetics: Determination of Transformer Operating Point.

http://www.femm.info/examples/mytransformer/mytransformer.zip

[8] Baltzis, K.B. (2008) The FEMM Package: A Simple, Fast, and Accurate Open Source Electromagnetic Tool in Science and Engineering. Journal of Engineering Science and Technology Review, 1, 83-89. https://doi.org/10.25103/jestr.011.18

[9] Baltzis, K.B. (2010) The Finite Element Method Magnetics (FEMM) Freeware Package: May It Serve as an Educational Tool in Teaching Electromagnetics? Education and Information Technologies, 15, 19-36. https://doi.org/10.1007/s10639-008-9082-8

[10] Íñiquez, J., et al. (2005) Magnetic Levitation by Induced Eddy Currents in NonMagnetic Conductors and Conductivity Measurements. European Journal of Physics, 26, 951-957. https://doi.org/10.1088/0143-0807/26/6/002

[11] Sinnadurai, R., Ting, C.M. and Zani, N.H.M. (2016) Analysis and Optimization of a Three Phase Linear Generator Using Finite Element Method Magnetics (FEMM). 2016 IEEE Student Conference on Research and Development (SCOReD), Kuala Lumpur, 13-14 December 2016, 1-6. https://doi.org/10.1109/SCORED.2016.7810092

[12] Pamme, N. (2006) Magnetism and Microfluidics. Lab on a Chip, 6, 24-38. https://doi.org/10.1039/B513005K

[13] Wichert, T. and Kub, H. (2005) Design and Optimization of Switched Reluctance Machines. Proceedings of the XLI International Symposium on Electrical Machines, Jarnołtówek, 14-17 June 2005, 10.

[14] Rotariu, O., Udrea, L.E., Strachan, N.J.C. and Badescu, V. (2005) Targeting Magnetic Carrier Particles in Tumor Microvasculature-A Numerical Study. Journal of Optoelectronics and Advanced Materials, 7, 3209-3218.

[15] Picker, R., Altarev, I., Bröcker,J., Gutsmiedl, E., Hartmann, J., Müller, A., Paul, S., Schott, W., Trinks, U. and Zimmer O. (2005) A Superconducting Magnet UCN Trap for Precise Neutron Lifetime Measurements. Journal of Research of the National Institute of Standards and Technology, 110, 357-360.

http://www.nist.gov/jres https://doi.org/10.6028/jres.110.053

[16] Zandsteeg, C.J. (2005) Design of a RoboCup Shooting Mechanism. Report 2005.147, Eindhoven University of Technology, Eindhoven.

[17] Acuña, M.H., Anderson, B.J., Russel, C.T., Wasilewski, P., Kletetschka, G., Zanetti, L. and Omidi, N. (2002) Near Magnetic Field Observations at 433 Eros: First Measurements from the Surface of an Asteroid. Icarus, 155, 220-228. https://doi.org/10.1006/icar.2001.6772

[18] Martignoni, A. (2003) Transformadores. 8th Edition, Editora Globo, São Paulo. (In 
Portuguese)

[19] Moses, A., Anderson, P., Jenkins, K. and Stanbury, H. (2019) Electrical Steels, Volume 1: Fundamentals and Basic Concepts. The IET Digital Library. https://doi.org/10.1049/PBPO157F

[20] Nogueira, A.F.L., Facchinello, G.G. and Ramos, L.A. (2013) Prediction of Magnetizing Currents in Power Transformers Using Numerically Simulated Open-Circuit Tests. International Journal of Research and Reviews in Applied Sciences, 17, 141-149. https://www.arpapress.com/Volumes/Vol17Issue2/IJRRAS_17_2_01.pdf

[21] https://www.femm.info/wiki/FAQ\#anchor27 


\section{Appendix A. Complex Permeability in Time-Harmonic Problems}

In time-harmonic problems, the complex permeability can be defined in different ways. In the following, two different definitions are briefly discussed.

\section{A1. The Complex Permeability Is Independent of the Frequency}

Let $H$ and $B$ represent the phasor vectors computed from the prescribed driving current $I$ and computed flux linkage $\lambda$ with the exciting winding, respectively. In one of the definitions of complex permeability, it is assumed that magnetic hysteresis creates a "fixed" time phase difference, $\phi_{\mathrm{h}}$, between vectors $\boldsymbol{B}$ and $\boldsymbol{H}$ that is independent of the frequency of excitation. This situation is illustrated in Figure 2(b). According to the illustration, the $\boldsymbol{B}$-field lags the $\boldsymbol{H}$-field by an angle $\phi_{\mathrm{h}}$, known as the hysteresis angle of the magnetic material. The complex-valued magnetic permeability, $\mu_{\mathrm{h}}$, is then defined by

$$
\mu_{\mathrm{h}}=\frac{\|B\|}{\|H\|} \mathrm{e}^{-j \phi_{\mathrm{h}}}=\mu_{\mathrm{r}} \mu_{0} \mathrm{e}^{-j \phi_{\mathrm{h}}} .
$$

where $\mu_{\mathrm{r}}$ is the magnetostatic relative permeability, and $\mu_{0}$ is the permeability of free space. In this approximate model, the hysteresis loop becomes an ellipse with its major axis making an angle of $\phi_{\mathrm{h}}$ radians with the $H$-axis [2].

In the electromagnetic field simulator FEMM, the time phase difference, $\phi_{\mathrm{h}}$, is part of the definition of a linear time-harmonic problem. According to the illustration of Figure A1, it is firstly necessary to specify the magnitude of the relative magnetic permeability in the $x$ - and $y$-directions. This is followed by the specification of the hysteresis-induced angles in the $x$ - and $y$-directions. The default hysteresis lag angles are $\phi_{\mathrm{hx}}=\phi_{\mathrm{hy}}=0^{\circ}$. In this example, the magnitude of the relative permeabilities for the $\mathrm{M}-36$ steel is the same in both directions, i.e., $\mu_{\mathrm{x}}=$ $\mu_{\mathrm{y}}=1616$

To make the matter concrete, let us consider the no-load operation of the test transformer with a $60 \mathrm{~Hz}$ driving current $I_{\mathrm{s}}=0.123 \mathrm{~mA}$ supplying the low-voltage winding, and a set of numeric simulations distinguished by the user-defined hysteresis angle $\phi_{\mathrm{h}}$. The driving current represents $4.5 \%$ of the winding's rated

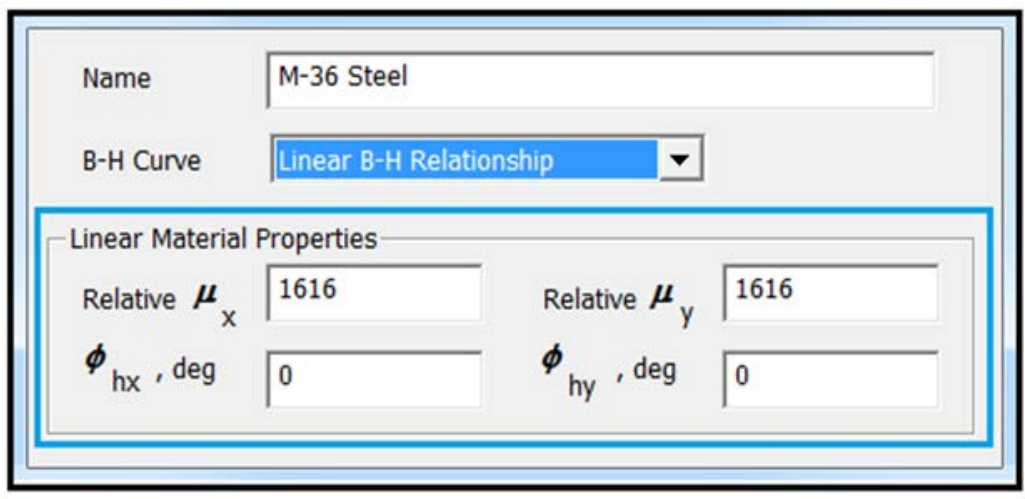

Figure A1. Input data for a linear time-harmonic problem. 
current and the transformer operates at rated terminal voltage. In this simplified analysis, it assumed that the hysteresis angles defined as part of the linear material properties are $\phi_{\mathrm{hx}}=\phi_{\mathrm{hy}}=\phi_{\mathrm{h}}$. In the sequence of simulations, the hysteresis lag angle varies from $0^{\circ}$ to $30^{\circ}$, in steps of $5^{\circ}$. In the problem definition, the special attributes of the M-36 steel laminations are: (i) electric conductivity of $2.0 \times$ $10^{6} \mathrm{~S} / \mathrm{m}$; (ii) thickness of $0.635 \mathrm{~mm}$; (iii) and fill factor of 0.98 . In the analysis, the figure of prime interest is the computed complex permeability. Results of the simulations are presented in Table A1 together with Figure A2 and Figure A3.

Values of the computed complex permeabilities are presented in columns 4 and 5 of Table A1, and their graphical representation is shown in Figure A2. In the plot, the idealized, user-defined relative permeabilities $\mu_{\mathrm{h}}=1616 \mathrm{e}^{-j \phi_{\mathrm{h}}}$ are marked with an asterisk, whereas the perceived, computed relative permeabilities are marked with a square.

It is important to note that, for each linear time-harmonic problem, this approximate model produces a unique value for the computed complex permeability,

Table A1. User-defined and computed complex permeabilities.

\begin{tabular}{|c|c|c|c|c|c|}
\hline \multirow{2}{*}{$\begin{array}{c}\text { Specified } \\
\text { hysteresis angle } \\
\text { (degree) }\end{array}$} & \multicolumn{2}{|c|}{ User-defined permeability } & \multicolumn{2}{|c|}{ Computed permeability } & \multirow{2}{*}{$\begin{array}{c}\text { Error in }|\mu| \\
\quad(\%)\end{array}$} \\
\hline & $\begin{array}{l}\text { Magnitude } \\
\text { (p.u.) }\end{array}$ & $\begin{array}{c}\text { Angle } \\
\text { (degree) }\end{array}$ & $\begin{array}{l}\text { Magnitude } \\
\text { (p.u.) }\end{array}$ & $\begin{array}{c}\text { Lag Angle } \\
\text { (degree) }\end{array}$ & \\
\hline $0^{\circ}$ & 1616 & $0^{\circ}$ & 1580.76 & -2.9 & 2.2 \\
\hline$-5^{\circ}$ & 1616 & $5^{\circ}$ & 1573.78 & -7.9 & 2.6 \\
\hline$-10^{\circ}$ & 1616 & $10^{\circ}$ & 1566.95 & -12.9 & 3.0 \\
\hline$-15^{\circ}$ & 1616 & $15^{\circ}$ & 1560.34 & -17.8 & 3.4 \\
\hline$-20^{\circ}$ & 1616 & $20^{\circ}$ & 1553.98 & -22.7 & 3.8 \\
\hline$-25^{\circ}$ & 1616 & $25^{\circ}$ & 1547.91 & -27.6 & 4.2 \\
\hline$-30^{\circ}$ & 1616 & $30^{\circ}$ & 1542.17 & -32.5 & 4.6 \\
\hline
\end{tabular}

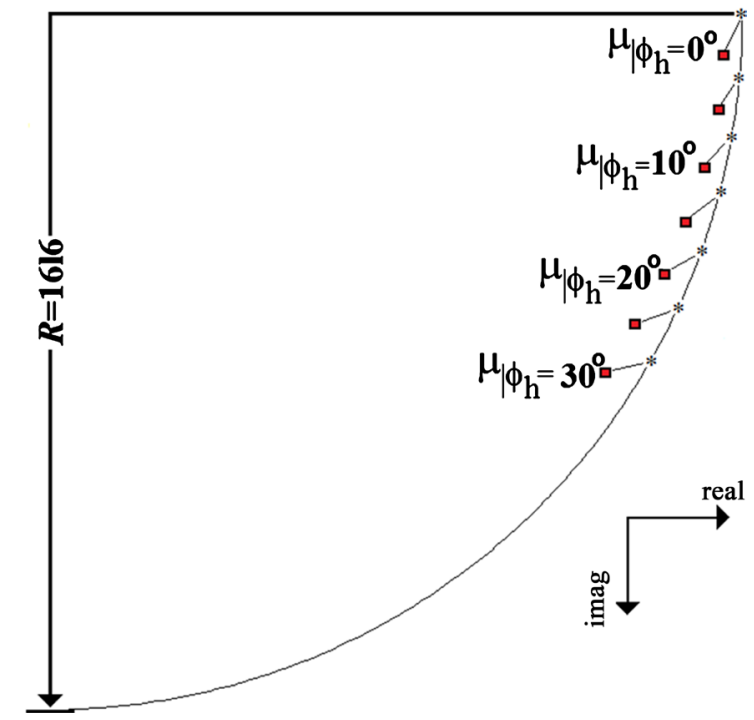

Figure A2. User-defined and computed complex permeabilities. 


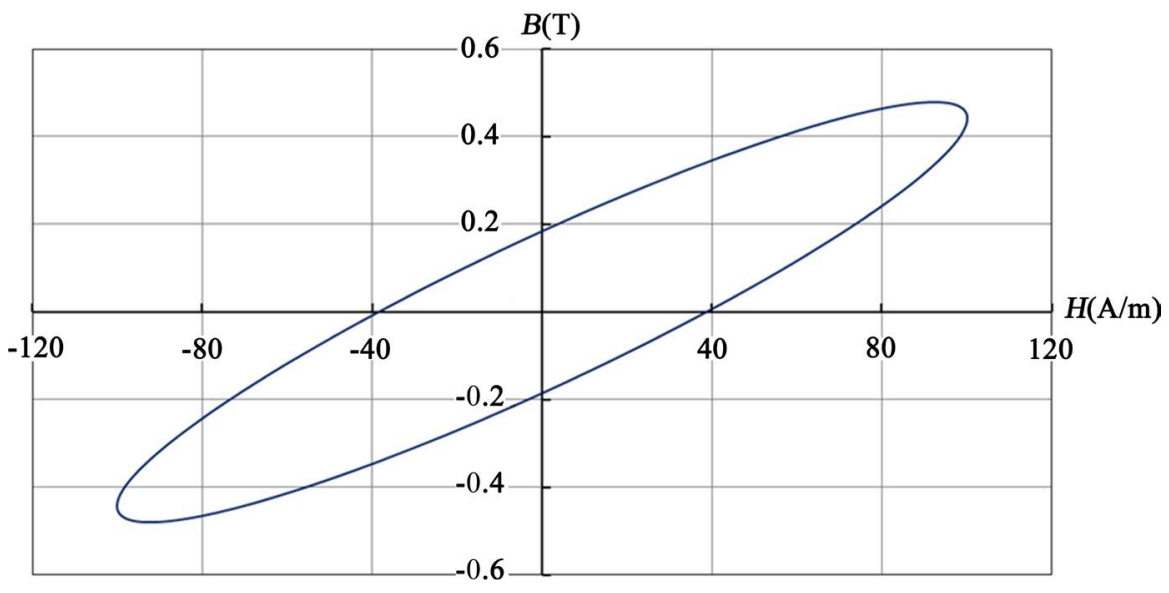

Figure A3. Approximate hysteresis loop when $\phi_{\mathrm{hx}}=\phi_{\mathrm{hy}}=20^{\circ}$.

$\mu_{\mathrm{h}}$, in the whole volume occupied by the laminated core. For the field problem where $\phi_{\mathrm{hx}}=\phi_{\mathrm{hy}}=20^{\circ}$, the time-harmonic solution gives $\mu_{\mathrm{x}}=\mu_{\mathrm{y}}=1433.61-\mathrm{j} 599.68$ p.u. at any point situated in the region of the laminated core. Observation of the results shows small discrepancies between computed and user-defined complex permeabilities. According to data presented in the $6^{\text {th }}$ column of Table A1, the percent error in computed magnitude varies from $2.2 \%$ to $4.6 \%$. The averaged absolute error in computed phase angle is $2.7^{\circ}$.

The approximate elliptical hysteresis loop for the field problem where $\phi_{\mathrm{hx}}=\phi_{\mathrm{hy}}$ $=20^{\circ}$ is exhibited in Figure A3. The vector fields $H$ and $B$ are calculated using (1) and (2). For a terminal driving current, $I$, given by

$$
I=123.037 \angle 0^{\circ} \mathrm{mA} \text {, }
$$

and a computed flux linkage, $\lambda$, given by

$$
\lambda=30.220 \angle-22.7^{\circ} \mathrm{mWb},
$$

the computed magnetic induction $\boldsymbol{B}$ is

$$
\boldsymbol{B}=0.48 \angle-22.7^{\circ} \mathrm{T},
$$

and magnetic field strength $H$ is

$$
\boldsymbol{H}=100 \angle 0^{\circ} \mathrm{A} / \mathrm{m} .
$$

\section{A2. The Complex Permeability Is Frequency-Dependent}

In time-harmonic problems involving thin laminations, the effect of eddy currents and hysteresis can be encapsulated in the effective, frequency-dependent permeability defined by

$$
\mu_{\text {eff }}=\frac{\mu_{\mathrm{r}} \mathrm{e}^{\frac{-j \phi_{\mathrm{h}}}{2}} \tanh \left[\frac{-j \phi_{\mathrm{h}}}{2} \sqrt{j \omega \sigma \mu_{\mathrm{r}} \mu_{0}} \frac{d}{2}\right]}{\sqrt{j \omega \sigma \mu_{\mathrm{r}} \mu_{0}} \frac{d}{2}},
$$

where $\phi_{\mathrm{h}}$ represents a constant phase lag between the $\boldsymbol{H}$ - and $\boldsymbol{B}$-fields, $\sigma$ is the electric conductivity of the laminations, $d$ is the thickness of individual lamina- 
tions, and $\omega$ is the angular frequency of excitation in $\mathrm{rad} / \mathrm{s}$. The term " $\omega \sigma \mu_{\mathrm{r}} \mu_{0}$ " present on the RHS of (A.6) reveals that, the calculation of the effective permeability considers the attenuation of the $H$-field below the surface of laminations due to the action of induced eddy currents.

\section{Appendix B. Magnetization Characteristic for the M-36 Steel}

The magnetization characteristic $B=B(H)$ for the M-36 steel expressed as a $1^{\text {st }}$ quadrant curve is shown in Figure B1. The increments along the horizontal axis are $100.0 \mathrm{~A} / \mathrm{m}$ between ticks, and the increments along the vertical axis are $0.2 \mathrm{~T}$. Values of the magnetic induction $B$ extend up to $1.50 \mathrm{~T}$.

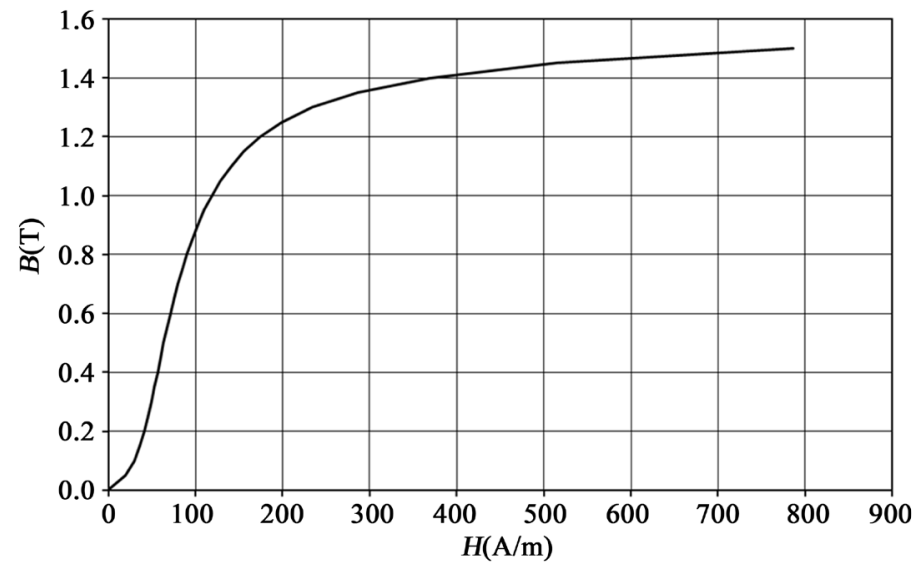

Figure B1. Magnetization characteristic for the M-36 steel. 